\title{
Rapid response of hypercortisolism to vandetanib treatment in a patient with advanced medullary thyroid cancer and ectopic Cushing syndrome
}

Fabián Pitoia', Fernanda Bueno', Angélica Schmidt', Sabrina Lucas', Graciela Cross' ${ }^{1}$

\begin{abstract}
SUMMARY
Medullary thyroid carcinoma (MTC) may rarely present with paraneoplastic syndromes. Among the most frequent ones are the appearance of diarrhea and ectopic Cushing syndrome (ECS). The ECS in the context of MTC is usually present in patients with distant metastatic disease. The use of drugs such as ketoconazole, metyrapone, somatostatin analogs and etomidate have been ineffective alternatives to control hypercortisolism in these patients. Bilateral adrenalectomy is often required to manage this situation. Recently, the use of tyrosine kinase inhibitors has been shown to be a useful tool to achieve eucortisolism in patients with metastatic MTC and ECS. We present a patient with sporadic advanced persistent and progressive MTC with lymph node and liver metastases, which after 16 years of followup developed an ECS. After one month of $300 \mathrm{mg} /$ day vandetanib treatment, a biochemical and clinical response of the ECS was achieved but it did not result in significant reduction of tumor burden. However the patient reached criteria for stable disease according to response evaluation criteria in solid tumors (RECIST 1.1) after 8 months of follow-up. Arch Endocrinol Metab. 2015;59(4):343-6
\end{abstract}

Keywords

Vandetanib; medullary thyroid cancer; ectopic Cushing syndrome
' División de Endocrinología, Hospital de Clínicas, Universidad de Buenos Aires Buenos Aires, Argentina

\section{Correspondence to:}

Fabián Pitoia

División de Endocrinología, Hospital de Clínicas,

Universidad de Buenos Aires, Av. Córdoba, $2351,5^{\circ}$ piso 1001 - Buenos Aires, Argentina fpitoia@intramed.net

Received on Jan/17/2015 Accepted on Apr/22/2015

DOI: 10.1590/2359-3997000000057

\section{INTRODUCTION}

$\mathrm{M}$ edullary thyroid carcinoma (MTC) accounts for less than $5 \%$ of all thyroid cancers. It arises from parafollicular or $\mathrm{C}$ cells, which are derived from embryological neural crest. Around $75 \%$ of MTC are sporadic and the rest of them are hereditary with an autosomal dominant pattern and a penetrance of up to $100 \%$. These cases are associated with mutations in the $R E T$ proto-oncogene in the context of what is known as multiple endocrine neoplasia (MEN): MEN 2A, 2B and familial MTC $(1,2)$.

The 10-year survival rate for patients with sporadic MTC is $96 \%$ if the disease is treated while the tumor is confined to the thyroid gland (3). However, distant metastases are observed at presentation in nearly $20 \%$ of patients (1). Of these, about $40 \%$ will die of the disease within 2 years after the diagnosis ( 3 ).

MTC produces specific serum markers, such as calcitonin. Furthermore, it can also secrete substances such as carcinoembryonic antigen (CEA), and less frequently, other peptides such as serotonin, substance $\mathrm{P}$, vasoactive intestinal peptide, adrenocorticotropic hormone $(\mathrm{ACTH})$, corticotropin releasing hormone $(\mathrm{CRH})$, catecholamine metabolites and histamine and calcitonin related peptide (4). The main complications that can occur as a consequence of the hypersecretion of these substances usually is diarrhea. On the other hand, the over secretion of ACTH or CRH may determine the appearance of ectopic Cushing syndrome (ECS) (1). The ECS may occur from the moment of the diagnosis of the MTC until more than 2 decades later (5-10). However, the ECS is a rare complication in patients with MTC. To our knowledge, only 50 cases of ECS secondary to MTC have been described in the literature (6). In general, these patients do not respond to conventional anti-cortisol treatments, and generally have a high mortality (6). Moreover, fifty percent of them will die from complications arising from severe hypercortisolism and only $20 \%$ survive longer than one year after the diagnosis of ECS (6).

Vandetanib is a once-daily oral tyrosine-kinase inhibitor which selectively targets the rearranged during transfection (RET) receptor, the epidermal growth factor receptor (EGFR), and also the vascular endothelium 
growth factor receptor (VEGFR) $(11,12)$. Vandetanib (Caprelsa $^{\circledR}, \mathrm{ZD} 6474$; AstraZeneca) is the first drug approved for the treatment of symptomatic and/or progressive MTC in patients with unresectable, locally advanced, or metastatic disease in the United States, Europe and also, in a number of countries around the world, which includes Argentina and Brazil. The study that led to this approval was the ZETA trial which showed a significant longer median progression-free survival (PFS) vs. placebo (30.5 vs. 19.3 months; $\mathrm{p}=0.001$ ) in this setting, (HR 0.46; 95\% CI 0.31 to $0.69 ; \mathrm{p}<0.001$ ) with an estimated 11-month prolongation of median PFS (10). Vandetanib also demonstrated significantly higher rates of objective response $(45 \%$ vs. $13 \%$ for placebo; $\mathrm{p}<0.001)$, and calcitonin biochemical response $(69 \%$ vs. $3 \%$ for placebo; $\mathrm{p}<0.001)(13)$.

The aim of this publication is to present a case of advanced MTC who developed an ECS that rapidly responded to vandetanib $300 \mathrm{mg}$ /day treatment, with a stabilization of disease progression of the MTC during follow-up. The patient provided written consent for the publication of this case report.

\section{CASE REPORT}

A 37 year-old woman with a diagnosis of sporadic MTC has been followed-up at our institution during all the course of her disease.

Sixteen years ago, a fine needle aspiration of a $13 \mathrm{~mm}$ diameter thyroid nodule yielded a diagnosis of MTC. She underwent a total thyroidectomy together with a right cervical neck dissection. Due to local and lymph node structural persistence, five subsequent surgeries were required: bilateral neck dissection, mediastinal lymph node dissection, resection of a right paratracheal local recurrence and, finally, removal of mediastinal nodes and a left supraclavicular lymphadenopathy. This last surgery was performed 2 years ago.

She sought medical attention for evaluation of asthenia, dry cough and functional class III dyspnea. Physical examination revealed hypertension (150/100 $\mathrm{mmHg}$ ), tachycardia (110 beats per minute), full moon facies, plethora, dorsal hump, asymmetry and marked collateral circulation in the left cervical and axillary level by the presence of edema. She also showed a $10 \mathrm{~cm}$ diameter hard-stone consistency, supraclavicular left mass.

The biochemical analysis showed calcitonin levels of $4200 \mathrm{pg} / \mathrm{mL}(\mathrm{NV}<5 \mathrm{pg} / \mathrm{mL})$, CEA $35 \mathrm{ng} / \mathrm{mL}(\mathrm{NV}<$ $4.6 \mathrm{ng} / \mathrm{mL})$ elevated plasma ACTH $(49 \mathrm{pg} / \mathrm{mL}, \mathrm{NV}<$ $46 \mathrm{pg} / \mathrm{mL}$ ), 24 hs urinary free cortisol (UFC) elevated in two occasions (400 and $600 \mathrm{ug} / 24 \mathrm{~h}, \mathrm{NV} 20-200$ $\mathrm{ug} / 24 \mathrm{hs}$ ), lack of suppression with $\mathrm{l}$ and $8 \mathrm{mg}$ dexamethasone (Serum cortisol of $22 \mathrm{ug} / \mathrm{dL}$ and $23 \mathrm{ug} / \mathrm{dL}$, respectively, with a basal value of serum cortisol of 19 $\mathrm{ug} / \mathrm{dL})$, and loss of normal circadian rhythm (22-23 hs UFC $45 \mathrm{ng} / \mathrm{mg}$ creatinine, $\mathrm{NV}<30 \mathrm{ng} / \mathrm{mg}$ creatinine). The MRI of the sellar region showed no abnormalities in the pituitary gland. A CT of the chest, abdomen and pelvis showed multiple enlarged lymph nodes in the left cervical and mediastinal region with diameters between 18-50 $\mathrm{mm}$, and multiple hypervascular focal liver lesions between 15 to $33 \mathrm{~mm}$ in diameter (Figure 1).
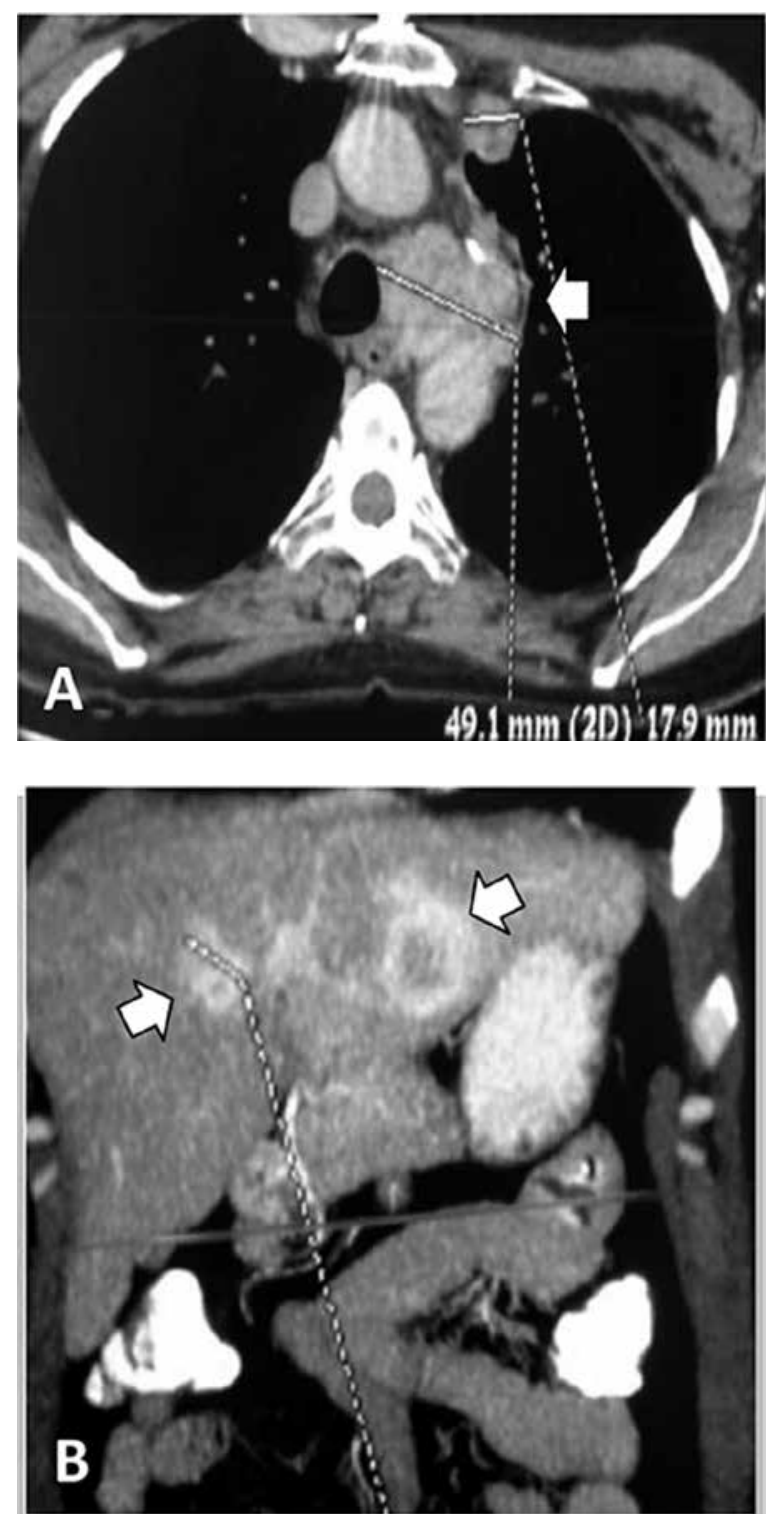

Figure 1. Computed tomography of the chest (A) showing multiple enlarged lymph nodes in the mediastinal region and nuclear magnetic resonance of the abdomen (B) demonstrating hypervascular hepatic lesions (white arrows) in a patient with ectopic Cushing syndrome due to metastatic medullary thyroid cancer. 
Due to metastatic, progressive and symptomatic MTC, we decided to start vandetanib $300 \mathrm{mg} /$ day oral treatment. As an adverse event to the drug, the patient presented a generalized grade 1 skin rash that occurred three weeks after vandetanib initiation. The rash resolved spontaneously under vandetanib $300 \mathrm{mg} /$ day treatment. Other laboratory assessments and ECG, including measurement of QT interval, were always normal.

One month after treatment initiation, the patient showed clinical response (normalization of blood pressure, decreased edema and decreased collateral circulation in the left chest and also, improvement of fatigue) and biochemical improvement (UFC: $68 \mathrm{ug} / 24 \mathrm{hs}$, calcitonin $1100 \mathrm{pg} / \mathrm{mL}$ ). These clinical and biochemical responses were kept until the time of this publication (8 months) (Figure 2).

Despite this improvement, imaging studies performed to evaluate tumor response showed no significant changes in the size of the metastatic lesions of the MTC. Currently, the patient maintains the benefits achieved with vandetanib treatment at full dosage.

\section{DISCUSSION}

The ECS is caused by the secretion of extra-pituitary ACTH or CRH, and represents 9 to $18 \%$ of cases of Cushing Syndrome (14). The most common causes of ECS are bronchial carcinoid and small cells lung cancer and infrequently, in 2 to $7.5 \%$ of cases, MTC (14).

Immunohistochemical analyses have shown that up to $40 \%$ of MTC usually secret ACTH (15). How- ever, it is only clinically evident in $0.6 \%$ of cases and it generally occurs in patients with advanced metastatic disease (6). ECS related to MTC diagnosis is based on the presence of hypercortisolism (with elevated or inappropriately normal ACTH) that is not suppressed by the $8 \mathrm{mg}$ dexamethasone test, absence of pituitary adenoma in MRI, and parallel progression of the Cushing Syndrome together with the MTC metastatic spread (6).

The treatment of these patients usually involves the use of drugs such as ketoconazole, metyrapone, somatostatin analogs and etomidate. All of these agents have low effectiveness in controlling hypercortisolism. As a consequence, bilateral adrenalectomy is frequently required to control this situation (6).

Recently, four cases of ECS associated to MTC with rapid response to tyrosine kinase inhibitors have been published: to sunitinib (16), sorafenib (17) and vandetanib treatments $(18,19)$ (Table 1$)$.

Vandetanib inhibits tyrosine kinase activity of the RET receptor, epidermal growth factor receptor (EGFR), and vascular endothelial growth factor receptor-2 (VEGFR), and has been proven effective in patients with and without mutations of the oncogene (20). Since its approval in 2011 by the Food and Drug Administration in the United States and in 2013 by the ANMAT (the health agency from Argentina), 2 case reports of successful treatment with vandetanib for ECS control in patients with advanced MTC have been published. In both cases there were no decrease in the size of the tumor mass $(18,19)$.

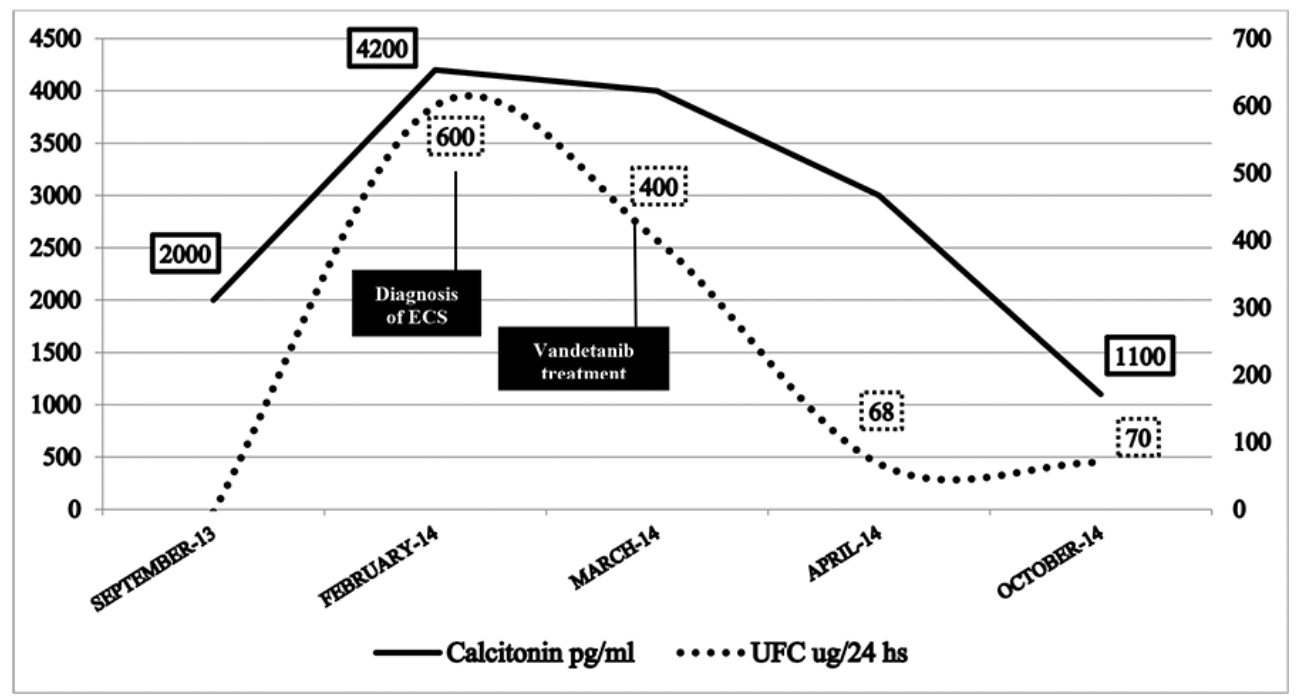

Figure 2. Changes in serum calcitonin and urinary free cortisol levels at the time of diagnosis and their outcome after vandetanib $300 \mathrm{mg} / \mathrm{day}$ oral treatment in a patient with ectopic Cushing syndrome due to a metastatic medullary thyroid carcinoma. 
Table 1. Published case reports in the literature of ectopic Cushing syndrome (ECS) due to medullary thyroid cancer who received tyrosine kinase inhibitors (TKI) treatment (the type of TKI, response of the ECS and the tumoral response are presented)

\begin{tabular}{|c|c|c|c|c|c|c|}
\hline Case report & MTC type & $\begin{array}{c}\text { Treatment } \\
\text { (drug/dosage) }\end{array}$ & $\begin{array}{l}\text { Treatment } \\
\text { duration } \\
\text { (months) }\end{array}$ & $\begin{array}{c}\text { Response of } \\
\text { hypercortisolism } \\
\text { (days) }\end{array}$ & $\begin{array}{l}\text { Tumoral } \\
\text { response }\end{array}$ & $\begin{array}{c}\text { Treatment } \\
\text { withdrawal/under } \\
\text { treatment }\end{array}$ \\
\hline Baudry and cols. (Ref. 18) & NR & Vandetanib $300 \mathrm{mg} / \mathrm{d}$ & 4.2 & 15 & SD & NR \\
\hline Nella and cols. (Ref. 19) & MEN 2B & Vandetanib $200 \mathrm{mg} / \mathrm{d}$ & 29 & 30 & SD & Tumoral progression \\
\hline Barroso-Sousa and cols. (Ref. 17) & Sporadic & Sorafenib 800 mg/d & 15 & 7 & SD & $\begin{array}{l}\text { Tumoral progression } \\
\text { and ESC recurrence }\end{array}$ \\
\hline Marques and cols. (Ref. 16) & Sporadic & $\begin{array}{c}\text { Sunitinib } 25 \mathrm{mg} / \mathrm{d}+ \\
\text { Metirapone }\end{array}$ & 5 & NR & PR & $\begin{array}{l}\text { Continues under } \\
\text { treatment }\end{array}$ \\
\hline
\end{tabular}

Ref.: reference number; NR: not reported; MEN 2B: multiple endocrine neoplasia 2B; SD (stable disease); PR (partial response).

In our patient, the hipercortisolism responded rapidly to vandetanib treatment (only one month). In addition, structural stability of the MTC was observed eight months after the prescription of the drug. This is coincident with the two previously described cases, suggesting the hypothesis that this kind of drugs would have a direct effect by blocking CRH or ACTH secretion by the tumor cells. This situation would be independent of their antiproliferative effect (18).

Therefore, we confirm previous findings showing that the treatment with vandetanib quickly and effectively controlled the ectopic ACTH/CRH secretion in this patient with advanced MTC. Additional studies are necessary to assess the impact on its use in other ECS etiologies.

Disclosure: Fabián Pitoia is a consultant and speaker bureau for AstraZeneca in Argentina. The remaining authors have nothing to declare.

\section{REFERENCES}

1. American Thyroid Association Guidelines Task Force, Kloos RT, Eng C, Evans DB, Francis GL, Gagel RF, Gharib H, et al. Medullary thyroid cancer: management guidelines of the American Thyroid Association. Thyroid. 2009;19(6):565-612.

2. Ceolin L, Siqueira DR, Romitti M, Ferreira CV, Maia AL. Molecular basis of medullary thyroid carcinoma: the role of RET polymorphisms. Int J Mol Sci. 2012;13(1):221-39.

3. Roman S, Lin R, Sosa JA. Prognosis of medullary thyroid carcinoma: demographic, clinical, and pathologic predictors of survival in 1252 cases. Cancer. 2006;107(9):2134-42.

4. de Groot JW, Kema IP, Breukelman H, van der Veer E, Wiggers T, Plukker JT, et al. Biochemical markers in the follow-up of medullary thyroid cancer. Thyroid. 2006;16(11):1163-70.

5. Chrisoulidou A, Pazaitou-Panayiotou K, Georgiou E, Boudina M, Kontogeorgos G, lakovou I, et al. Ectopic Cushing's syndrome due to $\mathrm{CRH}$ secreting liver metastasis in a patient with medullary thyroid carcinoma. Hormones (Athens). 2008;7(3):259-62.

6. Barbosa SL, Rodien P, Leboulleux S, Niccoli-Sire P, Kraimps JL, Caron $\mathrm{P}$, et al. Ectopic adrenocorticotropic hormone-syndrome in medullary carcinoma of the thyroid: a retrospective analysis and review of the literature. Thyroid. 2005;15(6):618-23.

7. Sand M, Uecker S, Bechara FG, Gelos M, Sand D, Wiese TH, et al. Simultaneous ectopic adrenocorticotropic hormone syndrome and adrenal metastasis of a medullary thyroid carcinoma causing paraneoplastic Cushing's syndrome. Int Semin Surg Oncol. 2007;4:15.

8. Singer K, Heiniger N, Thomas I, Worden FP, Menon RK, Chen M. Ectopic Cushing syndrome secondary to metastatic medullary thyroid cancer in a child with multiple endocrine neoplasia syndrome type 2B: clues to early diagnosis of the paraneoplastic syndromes. J Pediatr Endocrinol Metab. 2014;27(9-10):993-6.

9. Kurozumi A, Okada Y, Arao T, Nakamoto Y, Togashi K, Tanaka Y. Case of multiple endocrine neoplasia 2B with probable ectopic adrenocorticotropic hormone-secreting liver metastasis from medullary thyroid carcinoma. J UOEH. 2013;35(3):193-9.

10. Choi HS, Kim MJ, Moon CH, Yoon JH, Ku HR, Kang GW, et al. Medullary thyroid carcinoma with ectopic adrenocorticotropic hormone syndrome. Endocrinol Metab (Seoul). 2014;29(1):96-100.

11. Carlomagno F, Vitagliano D, Guida T, Ciardiello F, Tortora G, Vecchio G, et al. ZD6474, an orally available inhibitor of KDR tyrosine kinase activity, efficiently blocks oncogenic RET kinases. Cancer Res. 2002;62(24):7284-90.

12. Wedge SR, Ogilvie DJ, Dukes M, Kendrew J, Chester R, Jackson JA, et al. ZD6474 inhibits vascular endothelial growth factor signaling, angiogenesis, and tumor growth following oral administration. Cancer Res. 2002;62(16):4645-55.

13. Wells SA Jr, Robinson BG, Gagel RF, Dralle H, Fagin JA, Santoro $M$, et al. Vandetanib in patients with locally advanced or metastatic medullary thyroid cancer: a randomized, double-blind phase III trial. J Clin Oncol. 2012;30(2):134-41.

14. Ilias I,Torpy DJ, Pacak K, Mullen N, Wesley RA, Nieman LK. Cushing's syndrome due to ectopic corticotropin secretion: twenty years' experience at the National Institutes of Health. J Clin Endocrinol Metab. 2005;90(8):4955-62.

15. Kameya T, Shimosato Y, Adachi I, Abe K, Kasai N, Kimura K, et al. Immunohistochemical and ultrastructural analysis of medullary carcinoma of the thyroid in relation to hormone production. Am J Pathol. 1977;89(3):555-74.

16. Marques P, Vieira Mda S, Bugalho MJ. Ectopic Cushing in a patient with medullary thyroid carcinoma hypercortisolism control and tumor reduction with sunitinib. Endocrine. 2015;49(1):290-2.

17. Barroso-Sousa R, Lerario AM, Evangelista J, Papadia C, Lourenço DM Jr, Lin CS, et al. Complete resolution of hypercortisolism with sorafenib in a patient with advanced medullary thyroid carcinoma and ectopic $A C T H$ (adrenocorticotropic hormone) syndrome. Thyroid. 2014;24(6):1062-6.

18. Baudry C, Paepegaey AC, Groussin L. Reversal of Cushing's syndrome by vandetanib in medullary thyroid carcinoma. $N$ Engl J Med. 2013;369(6):584-6.

19. Nella AA, Lodish MB, Fox E, Balis FM, Quezado MM, Whitcomb $\mathrm{PO}$, et al. Vandetanib successfully controls medullary thyroid cancer-related Cushing syndrome in an adolescent patient. J Clin Endocrinol Metab. 2014;99(9):3055-9.

20. Durante C, Paciaroni A, Plasmati K, Trulli F, Filetti S. Vandetanib: opening a new treatment practice in advanced medullary thyroid carcinoma. Endocrine. 2013;44(2):334-42. 